\section{Estudo \\ CoDebate}

em Testão

Dlamejamento
Revista Estudo \& Debate, Lajeado, v. 24, n. 2, 2017. ISSN 1983-036X

DOI: http://dx.doi.org/10.22410/issn.1983-036X.v24i2a2017.1249

\title{
GESTÁO ESTRATÉGICA EM EMPRESAS FAMILIARES: UM METAESTUDO DE PUBLICAÇÓES NO PERÍODO ENTRE 2010 E 2015
}

\author{
Denise Casagrande da Rocha ${ }^{1}$, Gabriel Machado Braido², Ângela Maria Haberkamp ${ }^{3}$
}

\begin{abstract}
Resumo: Este artigo busca verificar o que foi pesquisado sobre gestão estratégica em empresas familiares no período entre 2010 e 2015, identificando as abordagens teóricas e metodológicas utilizadas e apontando sugestóes de pesquisas futuras, com base nos artigos investigados. Para alcançar estes objetivos, foi realizada a análise dos metadados, do metamétodo e da metateoria de 39 artigos obtidos a partir de busca nas bases de dados EBSCO Host e ISI Web of Knowledge. Identificamos que 82,5\% dos artigos foram publicados em revistas com fator de impacto e que Chrisman é o autor mais citado. As pesquisas qualitativas representam 53,85\% dos artigos analisados, e a Visão Baseada em Recursos, juntamente com a Teoria da Agência correspondem às abordagens teóricas utilizadas com maior frequência. Com base nas análises realizadas, também foram identificadas sugestôes de pesquisas futuras, agrupadas em quatro blocos temáticos.
\end{abstract}

Palavras-chave: Gestão estratégica. Estratégia. Empresas familiares. Metaestudo.

\section{STRATEGIC MANAGEMENT IN FAMILY BUSINESSES: A META-STUDY OF PUBLICATION IN THE PERIOD BETWEEN 2010 AND 2015}

\begin{abstract}
This paper aims to verify what has been researched about strategic management in family businesses in the period between 2010 and 2015, identifying the theoretical and methodological approaches used and pointing future research suggestions based on researched articles To achieve these goals, we performed the metadata, meta-method and meta-analysis of 39 articles obtained from searching the databases EBSCO Host and ISI Web of Knowledge. We found that $82.5 \%$ of articles were published in journals with impact factor and that Chrisman is the most cited author. Qualitative research represents $53.85 \%$ of the analyzed articles, and the Resource Based Vision, together with the Agency Theory, correspond to the most frequently theoretical
\end{abstract}

1 Doutoranda em Administração (Unisinos) e Mestre em Administração (PPGA/EA/UFRGS). É diretora Executiva da Denise Casagrande - Desenvolvimento de Pessoas e Organizaçóes. denise@denisecasagrande.com.br

2 Doutorando em Adminsitração (Unisinos) e Mestre em Administração (PPGA/EA/UFRGS). É professor assistente do Centro Universitário UNIVATES. gabrielb@univates.br

3 Doutoranda em Ciências Contábeis (Unisinos) e Mestre em Administração (PPGA/EA/UFRGS). É professora assistente do Centro Universitário UNIVATES. angelamh@univates.br 
approaches used. Based on the analyzes, it was also identified future research suggestions, grouped into four thematic blocks.

Keywords: Strategic Management. Strategy. Family businesses. Meta-study.

\section{INTRODUÇÃO}

Durante a década de 1990, o campo de produção científica em Administração parece ter se voltado para si mesmo, em uma análise crítica que objetivou apurar a qualidade, o rigor, a relevância e a originalidade dos diversos artigos publicados na área (CALDAS; TONELLI; LACOMBE, 2002). Devido ao aumento significativo na quantidade de publicaçóes observado nas últimas décadas, torna-se cada vez mais necessária a condução de balanços críticos e avaliações da qualidade em relação à quantidade dos trabalhos produzidos, bem como se estes avançam, de fato, no conhecimento considerando as lacunas e as oportunidades apontadas por estudos anteriores (SOUZA; REINERT; SPROSSER, 2009).

Diante disso, surgiram os metaestudos, analisando as mais diversas dimensóes da produção científica em cada uma dessas áreas (CALDAS; TONELLI; LACOMBE, 2002). Souza, Reinert e Sprosser (2009) constataram que a partir da comparação dos metaestudos nas diversas áreas da Administração, a mais frequente é a de "estratégia em organizaçôes", especialmente pelas temáticas relacionadas com estratégia, competitividade e vantagem competitiva. Contudo, embora existam importantes publicaçôes acerca destes temas, é necessário revisitar a literatura existente, bem como contribuir para a consolidação das pesquisas sobre a gestão estratégica em empresas familiares.

A gestão estratégica constitui-se de um campo acadêmico relativamente recente, que possui fragilidades no consenso sobre os próprios limites e significados, concorrendo e apresentando sobreposiçóes com outros campos, como a economia, sociologia, marketing, finanças e psicologia (NAG; HAMBRICK; CHEN, 2007). Porém, parecem não haver dúvidas quanto à relevância e contribuição da gestáo estratégica (para o alinhamento dos esforços em direção ao conjunto de objetivos e para a formulação, implementaçáo e controle do progresso destes), em empresas familiares ou náo familiares (SHARMA; CHRISMAN; CHUA, 1997). Para Terence (2008), é fundamental que sejam consideradas as peculiaridades das pequenas empresas no processo de criação das estratégias, pois os estudos nesta área geralmente são voltados para grandes corporaçóes.

No que se refere ao reconhecimento da área de empresas familiares como um campo acadêmico, a situação mostra-se semelhante. Curiosamente, embora seja histórica a existência de empresas constituídas por famílias, este tema passou a ser tratado com formalismo acadêmico após os anos 60, com a criação do Family Firm Institute (FFI) em 1986 e a Family Business Review em 1988 (SHARMA; CHRISMAN; GERSICK, 2012). No contexto brasileiro, Paiva, Oliveira e Melo (2008) analisaram a produção científica relacionada a empresas familiares. Os pesquisadores identificaram 83 artigos, concluindo que seria importante a expansão das pesquisas no país.

Embora desde entâo tenham ocorrido importantes avanços nesta trajetória, percebese que os temas correlatos a empresas familiares ainda carecem de reconhecimento como 
integrantes de uma disciplina independente, suficientemente robusta para caracterizar um campo acadêmico (STEWART; MINER, 2011). Para Bird et al. (2002), ao utilizar-se de teorias de outras disciplinas acadêmicas para explicar os fenômenos típicos das empresas familiares, os pesquisadores acabam não se apropriando das questôes pertinentes a este campo de pesquisa. Para o autor, desta forma, apenas oferecem contribuiçóes acanhadas para o desenvolvimento de teorias próprias, reafirmando o relativo atraso desta construçáo, tendo em vista as demandas do contexto de negócios. Neste sentido, aproximar as perspectivas de gestáo estratégica e de empresas familiares, representa uma oportunidade real de compartilhamento de ideias e de discussáo teórica, reforçando o amadurecimento destas áreas de pesquisa.

O compromisso emocional dos membros da família com a sobrevivência da empresa e a tendência em disseminar internamente o senso de orientação estratégica com visão de longo prazo e o conjunto de valores da família (CHIRICO; SALVATO, 2008; CHIRICO et al., 2011) qualifica a cultura organizacional, reforça a identidade coletiva e demonstra um campo fértil para reforçar a gestão estratégica em empresas familiares. Sob esta ótica, estes aspectos implicam no entendimento de que, mesmo existindo interesses particulares (individuais ou de uma ou mais famílias sócias), o consenso sobre os objetivos comuns a serem alcançados se sobrepóe aos interesses das partes envolvidas. Consequentemente, se torna necessária a formulação e a implementação de estratégias para orientar os esforços dos profissionais e acompanhar o progresso da empresa na direçáo definida, principalmente em uma visão de perpetuidade.

Diante desse contexto apresentado surge a seguinte questão de pesquisa: Quais são as abordagens teóricas e metodológicas predominantes nos estudos de gestáo estratégica em empresas familiares? Para responder a esta questão, este artigo apresenta os seguintes objetivos: (i) verificar o que foi publicado sobre gestão estratégica em empresas familiares nas bases de dados EBSCO Host e ISI Web of Knowledge no período entre 2010 e 2015; (ii) identificar quais são as abordagens teóricas e metodológicas utilizadas nesses estudos; e (iii) apontar sugestóes de pesquisas futuras, com base nos artigos investigados.

Para alcançar os objetivos propostos, este artigo está estruturado em 5 seçôes. Além desta introdutória, a seção 2 apresenta a revisão de literatura, abordando conceitos sobre gestão estratégica, empresas familiares e gestáo estratégica em empresas familiares; a seçấo 3 , trata dos procedimentos metodológicos adotados; a seção 4 refere-se à apresentação e discussão dos resultados encontrados; e a seção 5 apresenta as consideraçóes finais, seguido pelas referências utilizadas no estudo.

\section{REVISÃO DE LITERATURA}

Buscando facilitar o entendimento sobre a temática investigada neste artigo, esta revisão de literatura está dividida em 3 seções, a saber: gestão estratégica, empresas familiares e gestão estratégica em empresas familiares. 


\subsection{Gestáo estratégica}

Estratégia, de acordo com Porter (2009), é a compatibilização mútua das atividades de uma empresa, sendo que seu sucesso depende do desempenho positivo das atividades, bem como da integração entre elas, pois não havendo compatibilidade entre atividades, não existirá uma estratégia diferenciada e muito menos sustentabilidade. Mintzberg et al. (2006), por sua vez, conceituam estratégia como um conjunto de objetivos, políticas e planos responsáveis pela definição do escopo da empresa e de seus métodos de sobrevivência e sucesso.

Conhecer os principais obstáculos, avaliar as condiçôes estratégicas, tratar riscos e turbulências, bem como identificar e aproveitar oportunidades são procedimentos fundamentais para que as empresas formulem açóes sustentáveis, construindo caminhos e alternativas para implementação de suas estratégias (PONTES, 2012). Para o autor, a gestão estratégica possibilita a projeção de cenários futuros que auxiliarão as empresas na definição de seus objetivos, na análise de alternativas e na tomada de decisóes eficazes.

Apesar de eventuais ambiguidades, existe um consenso no campo da estratégia que entende a gestão estratégica sob a perspectiva da inter-relação de seis elementos fundamentais: (i) iniciativas estratégicas; (ii) processos internos da organização; (iii) gestores/executivos tomadores de decisóes estratégicas; (iv) recursos envolvidos; (v) desempenho e resultados; e (vi) firma/organização (NAG; HAMBRICK; CHEN, 2007).

Com o foco voltado para o entendimento da estratégia na prática, Jarzabkowski e Spee (2009) concordam que, em geral, a estratégia como prática não é a primeira agenda dos pesquisadores e nem das organizaçóes, mas que esta abordagem pode ser vista como o ápice de mudanças construtivistas e práticas mais amplas na pesquisa em gestão estratégica. Nesse sentido, conceituam estratégia na prática como a atividade que compreende as açóes, interaçóes e negociaçóes dos diferentes atores envolvidos, bem como nas práticas em que eles se apoiam para a realização deste processo. Em suma, a estratégia como prática preocupa-se com o fazer da estratégia, como quem faz, o que faz, como faz ou executa, o que usa e quais as implicações que essas práticas têm na formulação de estratégias e posterior execução da gestão estratégica (JARBKOWSKI; SPEE, 2009).

\subsection{Empresas familiares}

A despeito do entendimento de que as empresas familiares são o negócio cooperativo e associativo mais antigo da história, percebe-se que elas vêm se transformando ao longo dos anos e que chegam à atualidade ocupando um importante papel na economia mundial, sobretudo nos países emergentes, contribuindo para a criação de riquezas e geração de empregos (GOMEZ-MEJÍA et al., 2007). Dentro desta perspectiva, pesquisadores têm se dedicado a aprofundar a definiçãa e a compreensão deste formato de negócios, bem como das suas características estruturais e peculiaridades de gestão.

É consenso que a empresa ou negócio familiar típico caracteriza-se como uma organização de propriedade familiar, normalmente controlada por membros da família (SHANKER; ASTRACHAN, 1996; LANSBERG, 1999) e que por vezes transcende diferentes geraçóes de herdeiros (ANDERSON; REEB, 2003; GOMEZ-MEJIA et al., 
2007). Empresa familiar é, portanto, potencialmente transgeracional, gerida formalmente por membros de uma mesma família ou de um pequeno número de famílias, que trazem consigo uma visão implícita do seu ramo familiar sobre o negócio (SHARMA; CHRSIMAN; CHUA, 1997).

Neste sentido, a empresa familiar envolve a conjugação de características, dinâmicas e expectativas implícitas entre duas dimensões complementares: a família e o negócio (FLEMONS; COLE, 1992; GERSICK et al., 1997). Assim, exigem soluções diferenciadas quanto à gestão da estrutura societária e de propriedade, da governança corporativa e do planejamento de sucessão, especialmente para os membros da família que atuam no negócio (CHRISMAN; CHUA; SHARMA, 1999; CHRISMAN; CHUA; STEIER, 2003).

Somente a questão da propriedade de um negócio por uma ou mais famílias não é suficiente para caracterizá-lo como uma empresa familiar. Para tanto, é necessário adicionar a esta o envolvimento da família proprietária na gestão, bem como a visão compartilhada entre os membros sobre o potencial de benefícios que a empresa poderá gerar para a família através das geraçóes (BENNEDSEN; PEREZ-CONZALEZ; WOLFENZON, 2010; CHUA; CHRISMAN; SHARMA, 1999). Como os membros da família que atuam na empresa, em geral, dispóem de maior liberdade para agir unilateralmente, do que ocorreria em empresas não familiares (CARNEY, 2005), o comportamento das empresas familiares é distintamente influenciado pelos valores e pelas metas não-econômicas da família, bem como pelo seu envolvimento e compromisso emocional com o negócio e geração de riquezas econômicas e sócio emocionais para a família. (GÓMEZ-MEJÍA et al., 2007).

\subsection{Gestão estratégica em empresas familiares}

Estudiosos de empresas familiares têm se ocupado da compreensão edo estabelecimento de distinçôes existentes entre empresas familiares e não familiares (CHRISMAN; CHUA; SHARMA, 2005; SHARMA, 2004). Parece existir um senso comum de que as empresas de controle familiar são diferentes das empresas não-familiares quanto aos respectivos objetivos, visão e cultura (ARRÈGLE et al., 2007; CHUA; CHRISMAN; SHARMA, 1999; GOMEZ-MEJIA; NUNEZ-NIQUEL; GUTIERREZ, 2001; GOMEZ-MEJIA et al., 2007), bem como quanto à formulação de estratégias e à capacidade de gestão do negócio com base nestas (PATEL; PIEPER; HAIR JR., 2012).

Sob a ótica da gestão estratégica, Sharma, Chrisman e Chua (1997) observam que esta impacta as empresas familiares na performance organizacional como um todo, no comportamento para assunção de riscos e na própria conduta estratégica adotada (FISS; ZAJAC, 2004; GOMEZ-MEJIA et al., 2007; MILLER; LE BRETON-MILLER, 2005; PALMER, 1987). Assim, a cultura organizacional vigente (caracterizada pelo conjunto de valores expressos por meio dos comportamentos e açóes da liderança da família ao longo do tempo), influencia de maneira direta o pensamento estratégico em empresas familiares (POZA, 2007). Esta característica pode transformar-se em importante vantagem competitiva em termos de execução e desempenho para o negócio (WARD, 2006).

As diferenças na gestão estratégica entre empresas familiares e não familiares, não se referem, obrigatoriamente, somente aos desempenhos alcançados (operacional ou do 
negócio), uma vez que estes são mensurados com relação a execução e realização de um conjunto de metas e objetivos. É possível pensar-se que as principais diferenças, portanto, estão na definição do conjunto de metas, na maneira como estas são implementadas/ mantidas e no comportamento/envolvimento dos participantes no processo (SHARMA; CHRISMAN; CHUA, 1997). Em empresas familiares, a presença dos proprietários/donos na gestão da empresa como parte interessada confere, por vezes, maior poder e autoridade para perseguir as metas da família, além dos objetivos econômicos da empresa (CHRISMAN et al., 2012; KOTLAR; MASSIS, 2013).

A própria elaboração do planejamento estratégico em empresas familiares apresenta particularidades. Terence (2002) identificou que aspectos comportamentais, contextuais e estruturais exercem influência no planejamento estratégico destas empresas. Talvez porque em geral, proprietários/donos tendem a envolverem-se fortemente, influenciando todas as etapas do processo de gestão estratégica do negócio, enquanto que em empresas não familiares, as influências ocasionadas pela participação dos profissionais neste processo parecem menores (HARRIS; MARTINEZ; WARD, 1994).

\section{PROCEDIMENTOS METODOLÓGICOS}

Para a elaboração dessa pesquisa, inicialmente foram selecionados os artigos analisados dentro da temática de gestão estratégia em empresas familiares. Para tanto, as etapas de seleção apresentadas na Figura 1 foram seguidas.

Figura 1- Etapas para seleção de artigos

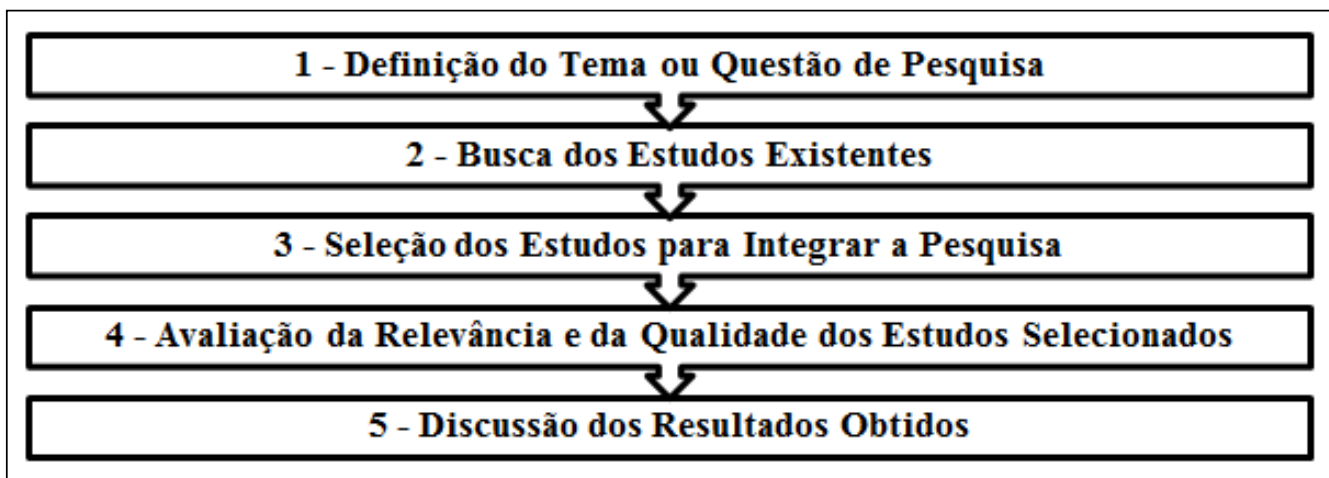

Fonte: adaptado de Dresch, Lacerda e Antunes (2015).

\section{Etapa 1 - Definição do tema ou questão de pesquisa}

Para a realização da presente pesquisa, definiu-se como problema a seguinte questão: quais são as abordagens teóricas e metodológicas predominantes nos estudos de gestão estratégica em empresas familiares? Neste sentido, por meio da realização deste metaestudo, pretende-se aprofundar os conhecimentos sobre a temática, bem como recolher evidências sobre a evolução das pesquisas (abordagens teóricas e metodológicas, principais temas 
abordados, lacunas para pesquisas futuras, etc.) sobre gestão estratégica em empresas familiares.

\section{Etapa 2 - Busca dos estudos existentes}

Nesta etapa definiu-se primeiramente um roteiro com os critérios a serem adotados para a busca dos estudos disponíveis sobre o tema definido. Para a seleção de artigos, utilizouse a busca avançada por tópico, com as seguintes palavras-chave: "strategic management" $e$ " family firms", compreendendo o período de publicaçóes entre 2010 e 2015, nas bases de dados EBSCO Host e ISI Web of Knowledge, atualizando o estudo de Massis et al. (2012), realizado com base em artigos publicados entre 1996 e 2010. O mapeamento ocorreu em 23 de outubro de 2015, onde identificou-se um total de 107 publicaçóes, conforme detalhado na Figura 2.

Figura 2- Mapeamento dos Estudos Existentes

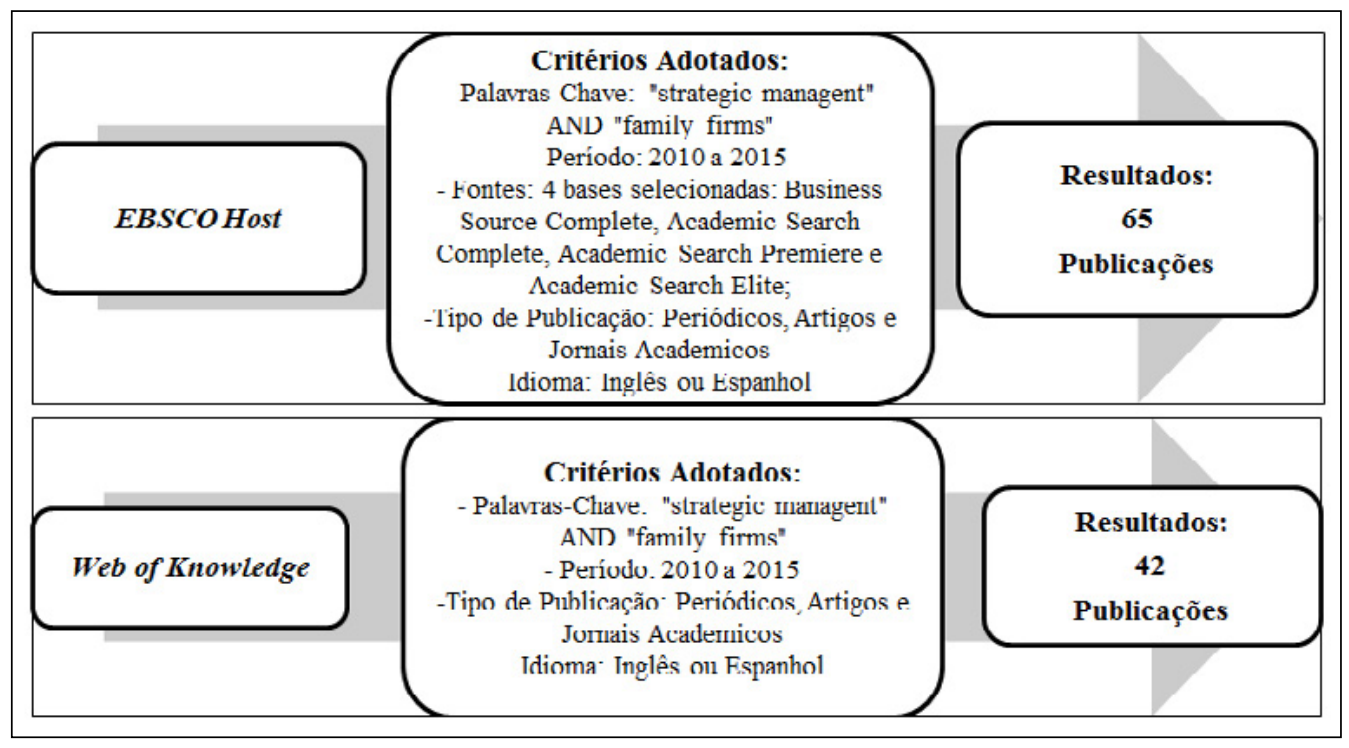

Fonte: elaborado pelos autores.

\section{Etapa 3 - Seleção dos estudos para integrar a pesquisa}

Com o objetivo de refinar a amostra de publicaçôes, nesta etapa foram analisados todos os resumos e palavras-chave dos artigos selecionados, a fim de identificar aqueles de fato relacionados à temática de gestão estratégia em empresas familiares, procedendo também a exclusão de revisões de literatura e eventuais casos de ensino da amostra.

Buscando diminuir a subjetividade e os vieses do pesquisador na seleção dos artigos pela análise do resumo, esta foi realizada individualmente pelos autores e, na sequência, os resultados foram confrontados. Os casos de discrepância foram separadamente analisados, buscando posteriormente o consenso sobre a manutenção ou exclusão do artigo. Após 
esta análise, foram selecionadas 39 publicaçóes que compóem a amostra deste estudo (ANEXO 1).

\section{Etapa 4 - Avaliação da relevância e da qualidade dos estudos selecionados}

Para a avaliação da relevância dos estudos selecionados, adotou-se a verificação do Fator de Impacto, no Journal Citation Reports, do Web of Knowledge, de cada periódico onde os artigos foram publicados, bem como a leitura completa do artigo para verificar se ele se enquadra no escopo desejado para pesquisa.

Alguns artigos selecionados estão publicados em revistas sem fator de impacto, porém optou-se por mantê-los no estudo. Optou-se por esta estratégia pois várias revistas são recentes e ainda não possuem de impacto definido.

\section{Etapa 5 - Discussáo dos resultados obtidos}

Para verificação dos artigos e discussão dos resultados destes, entre as várias técnicas de síntese que podem ser empregadas em análises de literatura, utilizou-se a abordagem de metaestudo, que de acordo com Hocayen-da-Silva, Rossoni e Ferreira Júnior (2008), permite a classificação dos procedimentos metodológicos, do referencial teórico, do número de autores por artigos, entre outras informaçóes relevantes, viabilizando conclusóes a respeito de campos de conhecimento ou da produçáo de uma área de estudos como um todo.

Assim, este estudo recolheu evidências nos artigos selecionados contemplando os três componentes de análise propostos por Dresch, Lacerda e Antunes (2015), que são: metadados, metamétodo e metateoria. A análise de metadados é essencialmente interpretativa e tem o objetivo de identificar similaridades e discrepâncias entre os estudos, em termos de fenômenos descritos, enquanto que o metamétodo analisa as abordagens metodológicas em seus diversos aspectos, enquanto que a metateoria pressupóe a análise dos pressupostos teóricos dos estudos selecionados (DRESCH; LACERDA; ANTUNES, 2015).

Relatados procedimentos metodológicos que orientaram a execução deste metaestudo, na próxima seção são apresentados e discutidos os resultados encontrados.

\section{APRESENTAÇÃO E DISCUSSÃO DOS RESULTADOS}

Esta seção apresenta as evidências mais significativas sobre a questão de pesquisa proposta neste estudo, observadas a partir da amostra de 39 artigos selecionados para compor este metaestudo. A seção está organizada em 4 subseções, a saber: análise de metadados, de metamétodo, de metateoria e sugestóes de estudos futuros.

\subsection{Análise de metadados}

A análise de metadados, segundo Dresch, Lacerda e Antunes (2015), é essencialmente interpretativa e tem o objetivo de identificar similaridades e discrepâncias entre os estudos, em termos de fenômenos descritos. Diante disso, inicialmente, na Tabela 1, são apresentados os periódicos nos quais os artigos foram publicados, bem como os respectivos fatores de impacto e o número de artigos publicados em cada um deles. 
Tabela 1 - Periódicos, fator de impacto e número de artigos

\begin{tabular}{lcccc}
\hline \multicolumn{1}{c}{ Periódico } & Impacto & No Artigos & \% & \% acum. \\
\hline Academy of Management Journal & 6,448 & 1 & $2,56 \%$ & $2,56 \%$ \\
Strategic Management Journal & 3,341 & 3 & $7,69 \%$ & $10,26 \%$ \\
Entrepreneurship: Theory and Practice & 3,144 & 14 & $35,90 \%$ & $46,15 \%$ \\
Asia Pacific Journal of Management & 2,091 & 1 & $2,56 \%$ & $48,72 \%$ \\
Strategic Entrepreneurship Journal & 2,000 & 4 & $10,26 \%$ & $58,97 \%$ \\
Small Business Economics & 1,795 & 1 & $2,56 \%$ & $61,54 \%$ \\
Journal of Business Research & 1,480 & 1 & $2,56 \%$ & $64,10 \%$ \\
Journal of Family Business Strategy & 1,381 & 2 & $5,13 \%$ & $69,23 \%$ \\
Journal of Small Business Management & 1,353 & 2 & $5,13 \%$ & $74,36 \%$ \\
Business History & 0,712 & 2 & $5,13 \%$ & $79,49 \%$ \\
RAE: Revista de Administração de Empresas & 0,176 & 1 & $2,56 \%$ & $82,05 \%$ \\
Academy of Strategic Management Journal & Sem fator & 1 & $2,56 \%$ & $84,62 \%$ \\
Cuadernos de Administración & Sem fator & 1 & $2,56 \%$ & $87,18 \%$ \\
EMAJ: Emerging Markets Journal & Sem fator & 1 & $2,56 \%$ & $89,74 \%$ \\
Estudios Gerenciales. & Sem fator & 1 & $2,56 \%$ & $92,31 \%$ \\
International Journal of Management Cases & Sem fator & 1 & $2,56 \%$ & $94,87 \%$ \\
Journal of Management \& Governance & Sem fator & 1 & $2,56 \%$ & $97,44 \%$ \\
Strategic Change & Sem fator & 1 & $2,56 \%$ & $100,00 \%$ \\
\hline & & $\mathbf{3 9}$ & $\mathbf{1 0 0} \%$ & \\
\hline
\end{tabular}

Fonte: elaborada pelos autores.

Observa-se que $82,05 \%$ dos artigos estão publicados em revistas que tem fator de impacto, com destaque para o Entrepreneurship: Theory and Practice, que contém 14 artigos (35,90\% do total), seguido pelo Strategic Entrepreneurship Journal, com 4 artigos (10,26\% do total) e pelo StrategicManagement Journal, com três artigos (7,69\% do total). O Jornal of Family Business Strategy, o Journal of Small Business Management e o Business History, contém dois artigos em cada respectivamente. Entre os demais periódicos com apenas um artigo publicado, destaca-se o Academy of Management Journal com fator de impacto de 6,448. Identificou-se, ainda, que $17,95 \%$ dos artigos selecionados (oito artigos do total) estáo publicados em revistas sem fator de impacto.

$\mathrm{Na}$ sequência, foi realizada a análise da frequência com que cada artigo da amostra foi citado por outros estudos, para identificar o impacto destas referências. Dessa forma, o Quadro 1 apresenta os 15 artigos mais citados na amostra, juntamente com seus autores e a quantidade de citaçóes recebidas. 
Quadro 1 - Artigos com maior número de citaçóes

\begin{tabular}{|c|c|c|}
\hline Autoria (ano) & Título do Artigo & Qtd. \\
\hline $\begin{array}{l}\text { CHRISMAN; PATEL } \\
\text { (2012) }\end{array}$ & $\begin{array}{l}\text { Variations in R\&D Investments of Family and Nonfamily Firms: } \\
\text { Behavioral Agency and Myopic Loss Aversion Perspectives }\end{array}$ & 74 \\
\hline $\begin{array}{l}\text { MILLER; LE BRETON- } \\
\text { MILLER; LESTER } \\
\text { (2010) }\end{array}$ & $\begin{array}{l}\text { Family Ownership and Acquisition Behavior in Publicly-traded } \\
\text { Companies }\end{array}$ & 49 \\
\hline $\begin{array}{l}\text { KOTLAR; MASSIS } \\
(2013)\end{array}$ & $\begin{array}{l}\text { Goal Setting in Family Firms: Goal Diversity, Social Interactions, } \\
\text { and Collective Commitment to Family-Centered Goals }\end{array}$ & 35 \\
\hline $\begin{array}{l}\text { LUMPKIN; BRIGHAM } \\
\text { (2011) }\end{array}$ & Long-Term Orientation and Intertemporal Choice in Family Firms & 35 \\
\hline CHIRICO et al. (2011) & $\begin{array}{l}\text { Resource Orchestration in Family Firms: Investigating How } \\
\text { Entrepreneurial Orientation, Generational Involvement, and } \\
\text { Participative Strategy Affect Performance }\end{array}$ & 23 \\
\hline $\begin{array}{l}\text { WENNBERG et al. } \\
\text { (2011) }\end{array}$ & $\begin{array}{l}\text { Implications of Intra-Family and External Ownership Transfer of } \\
\text { Familv Firms: Short-Term and Long-Term Performance Differences }\end{array}$ & 19 \\
\hline CARR et al. (2011) & $\begin{array}{l}\text { A Measure of Variations in Internal Social Capital Among Family } \\
\text { Firms }\end{array}$ & 17 \\
\hline $\begin{array}{l}\text { SHARMA; SALVATO } \\
\text { (2011) }\end{array}$ & $\begin{array}{l}\text { Commentary: Exploiting and Exploring New Opportunities Over } \\
\text { Life Cycle Stages of Family Firms }\end{array}$ & 14 \\
\hline $\begin{array}{l}\text { PATEL; CHRISMAN } \\
(2014) \\
\end{array}$ & Risk Abatement as a Strategy for R\&D Investments in Family Firms & 14 \\
\hline MAHTO et al. (2010) & Satisfaction With Firm Performance in Family Businesses & 10 \\
\hline HOLT (2012) & $\begin{array}{l}\text { Strategic Decisions Within Family Firms: Understanding the } \\
\text { Controlling Family's Receptivity to Internationalization }\end{array}$ & 9 \\
\hline $\begin{array}{l}\text { LUMPKIN; STEIER; } \\
\text { WRIGHT (2011) }\end{array}$ & Strategic Entrepreneurship in Family Business & 9 \\
\hline $\begin{array}{l}\text { CHRISMAN et al. } \\
\text { (2013) }\end{array}$ & $\begin{array}{l}\text { The Influence of Family Goals, Governance, and Resources on Firm } \\
\text { Outcomes }\end{array}$ & 8 \\
\hline $\begin{array}{l}\text { EDDLESTON et al. } \\
(2013)\end{array}$ & Planning for Growth: Life Stage Differ & 6 \\
\hline ACQUAAH (2012) & $\begin{array}{l}\text { Social Networking Relationships, Firm-Specific Managerial } \\
\text { Experience and Firm Performance in a Transition Economy: A } \\
\text { Comparative Analysis of Family Owned and Nonfamily Firms }\end{array}$ & 5 \\
\hline
\end{tabular}

Fonte: elaborado pelos autores.

$\mathrm{Na}$ análise da frequência, destaca-se o artigo de Chrisman e Patel (2012) com 74 citaçóes, seguido pelo estudo de Miller, Le Breton-Miller e Lester (2010), com 49 citaçóes e Kotlar e Massis (2013) e Lumpkin e Brigham (2011), com 35 citaçôes cada.

Buscando conhecer os principais pesquisadores envolvidos na temática de gestão estratégica em empresas familiares, procedeu-se a análise de autoria das publicaçóes, onde foi possível identificar que 98 autores foram responsáveis pela publicação dos 39 artigos. O número de autores por artigo variou entre 1 e 5 , sendo que a maioria dos estudos apresenta 2 autores $(35,90 \%)$ ou 4 autores $(30,77 \%)$.

O Quadro 2 demonstra os autores com o maior número de publicações (2 ou 3 artigos) na amostra selecionada. Vale ressaltar que os demais autores que não estão relacionados no quadro tiveram apenas uma publicação compondo a amostra. Observa-se 
que Sharma e Steier foram responsáveis pela autoria de 3 artigos cada, o que analisado em conjunto corresponde a 15,38\% do total de artigos publicados na amostra selecionada. Os demais autores relacionados possuem 2 artigos publicados cada.

Quadro 2 - Autores com o maior número de artigos publicados

\begin{tabular}{|l|c|}
\hline \multicolumn{1}{|c|}{ Autor } & No de Artigos \\
\hline SHARMA, P. & 3 \\
\hline STEIER, L. & 3 \\
\hline CHRISMAN, J. J. & 2 \\
\hline CHUA, J. H. & 2 \\
\hline DE MASSIS, A & 2 \\
\hline EDDLESTON, K. A. & 2 \\
\hline KELLERMANNS, F. W; & 2 \\
\hline KOTLAR, J; & 2 \\
\hline LUMPKIN, G. T. & 2 \\
\hline O'REGAN, N. & 2 \\
\hline PATEL, P. C. & 2 \\
\hline WRIGHT, M. & 2 \\
\hline
\end{tabular}

Fonte: elaborado pelos autores.

Na sequência, foi realizado o levantamento de todos os autores citados nos artigos analisados, para identificar quais são os principais autores que vêm embasando os estudos realizados nesta temática. $\mathrm{O}$ Quadro 3 apresenta os autores que foram citados 5 ou mais vezes nos 39 artigos analisados neste metaestudo.

Quadro 3 - Principais autores citados nos artigos analisados

\begin{tabular}{|l|c|}
\hline \multicolumn{1}{|c|}{ Autor } & No Citaçóes \\
\hline CHRISMAN, J.J. & 20 \\
\hline CHUA, J.H & 15 \\
\hline SHARMA, P. & 13 \\
\hline KELLERMANNS, F. W. & 8 \\
\hline NORDQVIST, M. & 8 \\
\hline CHIRICO, F. & 7 \\
\hline ZAHRA, S.A. & 6 \\
\hline ZELLWWEGER, T. M. & 6 \\
\hline EDDLESTON, K. A. & 5 \\
\hline HITT, M.A. & 5 \\
\hline SALVATO, C. & 5 \\
\hline SIRMON, D.G. & 5 \\
\hline STEIER, L. P. & 5 \\
\hline
\end{tabular}

Fonte: elaborado pelos autores. 
Observa-se que dos 13 autores citados, destacam-se 5 com mais de 8 citaçóes, a saber: Chrisman (com 20 citaçóes), Chua (15 citações), Sharma (13 citaçôes) e Kellermanns e Nordqvist (com 8 citações cada). É interessante ressaltar, ainda, que 6 destes pesquisadores (Chrisman, Chua, Sharma, Kellermanns, Eddleston e Steier) são autores de 2 ou 3 artigos selecionados para amostra deste metaestudo, conforme apresentado no Quadro 2.

Buscando evidenciar as principais referências sobre gestão estratégica e empresas familiares, também foi realizada uma análise das referências mencionadas nos artigos investigados. O Quadro 4 apresenta 7 referências, as quais foram citadas mais de 5 vezes nos estudos analisados, juntamente com a sua autoria.

Quadro 4-Referências mais citadas nos artigos analisados

\begin{tabular}{|l|l|c|}
\hline \multicolumn{1}{|c|}{ Autoria (ano) } & \multicolumn{1}{|c|}{ Título } & Qtde. \\
\hline ARREGLE et al. (2007) & $\begin{array}{l}\text { The development of organizational social capital: } \\
\text { attributes of family firms }\end{array}$ & 14 \\
\hline SIRMONN; HITT (2003) & $\begin{array}{l}\text { Managing resources: linking unique resources, } \\
\text { management, and wealth creation in family firms }\end{array}$ & 14 \\
\hline COVIN; GREEN; SLEVIN (2006) & $\begin{array}{l}\text { Strategic process effects on the entrepreneurial } \\
\text { orientation-sales growth rate relationship }\end{array}$ & 12 \\
\hline $\begin{array}{l}\text { HABBERSHON; WILLIAMS } \\
\text { (1999) }\end{array}$ & $\begin{array}{l}\text { A resource-based framework for assessing strategic } \\
\text { advantage of family firms }\end{array}$ & 11 \\
\hline $\begin{array}{l}\text { CHRISMAN; CHUA; SHARMA } \\
\text { (2005) }\end{array}$ & $\begin{array}{l}\text { Trends and directions in the development of a } \\
\text { strategic management theory of the family firm }\end{array}$ & 7 \\
\hline $\begin{array}{l}\text { SHARMA; CHRISMAN; CHUA } \\
\text { (2003) }\end{array}$ & $\begin{array}{l}\text { Predictors of satisfaction with the succession process } \\
\text { in family firms }\end{array}$ & 5 \\
\hline $\begin{array}{l}\text { CABRERA-SUÁREZ; SAÁ- } \\
\text { PÉREZ; GARCÍA-ALMEIDA } \\
\text { (2001) }\end{array}$ & $\begin{array}{l}\text { The succession process from a resource-and knowledge- } \\
\text { based view of the family firm }\end{array}$ & 5 \\
\hline
\end{tabular}

Fonte: elaborado pelos autores.

Apesar da presença dos temas gestão estratégica e empresa familiar em todos os artigos analisados, buscou-se entender melhor que outros temas relacionados a estes têm sido objeto de investigação dos pesquisadores os últimos 5 anos. Para tanto, realizou-se esta verificação nos artigos, por meio da análise das respectivas palavras chave, abstracts e tópicos gerais contidos na estrutura e nos referenciais teóricos dos estudos. Esta análise resultou na identificação de mais de 60 assuntos tratados nos artigos, que foram reunidos em blocos temáticos considerando as suas similaridades.

Deste modo, identificou-se 5 blocos temáticos nos estudos sobre gestão estratégica em empresas familiares, a saber: gestão estratégica (propriamente dita), governança corporativa, gestão operacional, gestão de pessoas e cultura organizacional e gestão financeira, conforme ilustrado na Figura 3. 
Figura 3 - Principais blocos temáticos dos artigos analisados

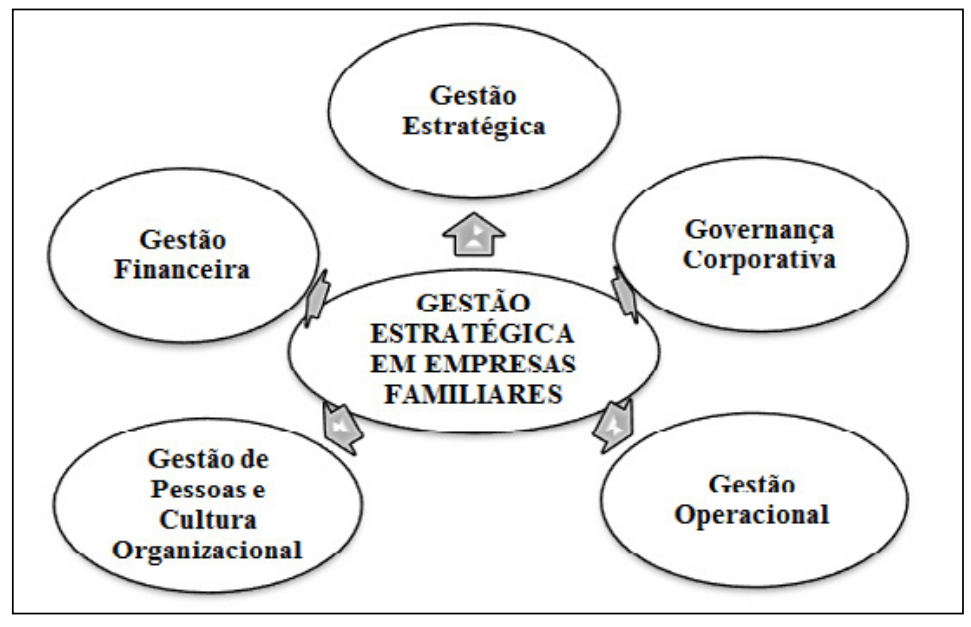

Fonte: elaborado pelos autores.

De forma específica, cada bloco temático engloba temas variados, correlatos ao tema central. No que se refere à gestão estratégica, com base na visão de longo prazo, as pesquisas abordam planejamento estratégico e gestáo estratégica dos negócios; competitividade e vantagem competitiva sustentável; inovação e aprendizagem organizacional, entre outros. No bloco da governança corporativa os temas centrais são: a orientação empreendedora, empreendedorismo e empreendimentos familiares; transição de geraçóes e planejamento de sucessão; governança corporativa e participativa; estrutura societária e propriedade da empresa, entre outros.

O foco dos estudos relacionados à gestáo operacional tem ênfase na visão de curto prazo, orientada para metas, indicadores e desempenho da empresa; gestão de recursos; análise comparativa do desempenho dos $\mathrm{CEO}$ familiares versus não-familiares; gestão industrial, produtividade e eficiência operacional. Já em relação à gestão de pessoas e cultura organizacional, os principais tópicos referem-se aos valores da família e da empresa; redes, laços e interaçôes sociais entre a família e os profissionais; capital humano, social e emocional da empresa familiar; competências e eficiência; conflitos familiares, entre outros. Por fim, os artigos sobre gestâo financeira compreendem principalmente temáticas relacionadas à análise de atividades/oportunidades econômicas; investimentos gerais e investimentos específicos em pesquisa e desenvolvimento; segurança e risco econômico financeiro da empresa; endividamento, gestão de caixa e geração de valor econômico.

De Massis et al. (2012) analisaram os estudos sobre negócios familiares publicados entre 1996 e 2010 e identificaram que temas como governança corporativa, sucessão, desempenho econômico, recursos e vantagem competitiva e empreendedorismo e inovação, eram prioritários (nesta ordem de importância). Atualmente, mesmo considerando-se a relevância e a complementariedade dos temas relacionados à gestão estratégica de empresas familiares de maneira mais ampla, assuntos como gestão estratégica (propriamente dita, 
incluindo processos e práticas) e governança corporativa caracterizam-se como prioritários, destacando-se nos artigos analisados.

\subsection{Análise de metateoria}

Nesta etapa do trabalho buscou-se realizar a análise de metateoria, a qual pressupóe a identificação das bases teóricas dos estudos selecionados (DRESCH; LACERDA; ANTUNES, 2015). Diante disso, verificou-se que 13 artigos (33,33\% do total) não utilizaram abordagens teóricas para embasar os seus estudos, enquanto que os outros 26 artigos (66,66\% do total) utilizaram 23 abordagens teóricas diferentes, as quais são apresentadas na Tabela 2, juntamente com a sua frequência de utilização. Vale ressaltar que vários artigos utilizam uma combinação de abordagens teóricas em suas análises, fato que justifica a frequência total de 47 abordagens teóricas nos 39 artigos analisados.

Tabela 2 - Abordagens teóricas utilizadas nos artigos analisados

\begin{tabular}{lccc}
\hline \multicolumn{1}{c}{ Abordagem Teórica } & No Artigos & \% & \% acum. \\
\hline Visão Baseada em Recursos (RBV) & 8 & $17,02 \%$ & $17,02 \%$ \\
Teoria da Agência & 7 & $14,89 \%$ & $31,91 \%$ \\
Capacidades Dinâmicas & 3 & $6,38 \%$ & $38,30 \%$ \\
Teoria Comportamental & 3 & $6,38 \%$ & $44,68 \%$ \\
Teoria Institucional & 3 & $6,38 \%$ & $51,06 \%$ \\
Teoria Prospectiva & 3 & $6,38 \%$ & $57,45 \%$ \\
Stewardship Theory & 2 & $4,26 \%$ & $61,70 \%$ \\
Teoria da Firma & 2 & $4,26 \%$ & $65,96 \%$ \\
Teoria do Capital Social & 2 & $4,26 \%$ & $70,21 \%$ \\
Teoria do Controle & 1 & $2,13 \%$ & $72,34 \%$ \\
Microteoria Econômica & 1 & $2,13 \%$ & $74,47 \%$ \\
Resource Orchestration & 1 & $2,13 \%$ & $76,60 \%$ \\
Teoria da Identidade Social & 1 & $2,13 \%$ & $78,72 \%$ \\
Teoria da Escolha Estratégica & 1 & $2,13 \%$ & $80,85 \%$ \\
Teoria da Aprendizagem Organizacional & 1 & $2,13 \%$ & $82,98 \%$ \\
Teoria da Contingência & 1 & $2,13 \%$ & $85,11 \%$ \\
Teoria da Imagem & 1 & $2,13 \%$ & $87,23 \%$ \\
Teoria da Rede Social & 1 & $2,13 \%$ & $89,36 \%$ \\
Teoria da Regulamentaçáo (RFT) & 1 & $2,13 \%$ & $91,49 \%$ \\
Teoria da Troca Social & 1 & $2,13 \%$ & $93,62 \%$ \\
Teoria do Ponto de Referência Estratégico & 1 & $2,13 \%$ & $95,74 \%$ \\
Teoria dos Jogos & 1 & $2,13 \%$ & $97,87 \%$ \\
Teoria dos Stakeholders & $\mathbf{1 0 0 \%}$ & $100,00 \%$ \\
\hline & & & \\
\hline
\end{tabular}

Fonte: elaborada pelos autores. 
A variedade de teorias utilizadas nos artigos analisados pode sugerir o interesse dos pesquisadores em abordar a perspectiva das empresas familiares a partir de "diversas lentes teóricas". Ao mesmo tempo demonstra a inexistência de teorias específicas voltadas para esta disciplina e reafirma a necessidade de os estudiosos utilizarem teorias de outros campos para embasar as pesquisas nesta área, conforme já haviam constatado Bird et al. (2002).

Neste sentido, a Visão Baseada em Recursos (RBV) destaca-se como a abordagem mais recorrente, tendo sido utilizada como embasamento para 8 estudos (17,02\% do total). Conforme Barney e Hesterly (2007), na perspectiva da RBV, as estratégias são definidas com vistas à potencialização dos ativos internos (recursos e capacidades controlados pela empresa). A análise dos ativos internos, bem como a identificação do potencial destes para geração de vantagens competitivas para a empresa, é realizada considerando 4 dimensóes: valor, raridade, imitabilidade e organizaçáo (BARNEY; HESTERLY, 2007).

Chrisman, Chua e Sharma (2005) apontam, também sob a ótica da RBV, que o desenvolvimento de uma teoria voltada para empresas familiares deve clarificar a compreensão do envolvimento da família na definiçẫo das estratégias e na gestão da empresa, como um recurso ou capacidade intangível e que pelas suas singularidades pode configurarse como algo valioso, raro, não imitável e insubstituível, resultando por vezes em vantagem competitiva para os negócios familiares.

Por fim, Teece, Pisano e Shuen (1997) acreditam que é exatamente na dimensão da aquisição de competências, aprendizagem, acúmulo de ativos intangíveis e invisíveis, que está o grande potencial das contribuições da RBV para a definição e gestâo da estratégia nas organizaçóes.

Observa-se também que a Teoria da Agência embasou 7 artigos (14,89\% do total). Sob esta perspectiva teórica, a gestão estratégica orienta-se para constituição de uma organização eficiente, caracterizada pelo equilíbrio na relação entre o agente e o principal, informaçôes e riscos, etc. (EISENHARDT, 1989) e pela administração de questóes relacionadas à agência (relaçóes entre os investidores e os gestores) e a discricionariedade diretiva (comportamentos oportunistas dos gestores) (EISENHARDT, 1985). Nesta abordagem, eventuais conflitos decorrentes do desequilíbrio dos aspectos mencionados implicam em custos e, portanto, devem ser estrategicamente mitigados.

Deste modo, em se tratando de empresas familiares, a Teoria da Agência oferece também subsídios importantes para o melhor entendimento do contrato e do compromisso entre administradores e proprietários, bem como do desempenho e da confiança implícita entre ambos (HENDRIKSEN; VAN BREDA, 1999).

Outras abordagens teóricas, como Capacidades Dinâmicas, Teoria Comportamental, Teoria Institucional e a Teoria Prospectiva serviram de referencial para 3 estudos cada, correspondendo cada uma delas a 6,38\% do total. As demais abordagens teóricas (utilizadas em apenas uma ou 2 pesquisas cada) estão relacionadas na Tabela 2. 


\subsection{Análise do metamétodo}

O metamétodo analisa as abordagens metodológicas em seus diversos aspectos (DRESCH; LACERDA; ANTUNES, 2015). Assim, esta seção apresenta uma análise das abordagens metodológicas dos artigos selecionados para este estudo.

$\mathrm{Na}$ análise realizada, identificou-se as abordagens metodológicas utilizadas, observando-se uma leve tendência à ocorrência de pesquisas qualitativas, visto terem sido realizadas por $53,85 \%$ dos artigos, enquanto que as pesquisas quantitativas representaram $43,59 \%$ dos estudos que pertencem a amostra selecionada. A abordagem mista, integrando as metodologias qualitativa e quantitativa, foi utilizada em apenas um estudo, representando 2,56\% da amostra total. Estes resultados podem ser visualizados na Tabela 3.

Tabela 3 - Abordagens metodológicas

\begin{tabular}{lcrr}
\hline \multicolumn{1}{c}{ Abordagem } & Qtde. & \multicolumn{1}{c}{$\%$} & \multicolumn{1}{c}{ Acum. } \\
\hline Qualitativa & 21 & $53,85 \%$ & $53,85 \%$ \\
Quantitativa & 17 & $43,59 \%$ & $97,44 \%$ \\
Mista & 1 & $2,56 \%$ & $100,00 \%$ \\
\hline Total & $\mathbf{3 9}$ & $\mathbf{9 7 , 4 4 \%}$ & \\
\hline
\end{tabular}

Fonte: elaborado pelos autores.

Após a identificação das abordagens metodológicas empregadas nos estudos de gestão estratégica em empresas familiares, buscou-se verificar quais as técnicas de coletas de dados mais utilizadas pelos autores nestas pesquisas. Cabe ressaltar que dos 39 artigos analisados, 13 classificam-se como teóricos, não utilizando técnicas de coletas de dados, mas propondo frameworks ou modelos a partir de revisóes de literatura.

Dessa forma, a Tabela 4 apresenta as principais técnicas de coletas de dados (classificadas conforme Klein et al., 2015) utilizadas nos 26 artigos empíricos analisados. É possível observar que as 5 diferentes técnicas empregadas, foram combinadas em algumas pesquisas (37 utilizaçóes no total), o que permite afirmar que alguns dos artigos valeram-se de mais de uma técnica de coleta de dados, especialmente aquele artigo que utilizou uma abordagem mista (qualitativa e quantitativa).

Tabela 4 - Técnicas de coleta de dados

\begin{tabular}{lccr}
\hline \multicolumn{1}{c}{ Técnica } & No Artigos & \% & \% acumul. \\
\hline Questionário & 14 & $37,84 \%$ & $37,84 \%$ \\
Documentos & 10 & $27,03 \%$ & $64,86 \%$ \\
Entrevistas & 8 & $21,62 \%$ & $86,49 \%$ \\
Observações & 4 & $10,81 \%$ & $97,30 \%$ \\
Grupo de foco & 1 & $2,70 \%$ & $100,00 \%$ \\
\hline \multicolumn{1}{c}{ Total } & $\mathbf{3 7}$ & $\mathbf{1 0 0 , 0 0 \%}$ & \\
\hline
\end{tabular}

Fonte: elaborado pelos autores. 
No que se refere às técnicas de coletas de dados, destacam-se o questionário, utilizado em $37,84 \%$ dos estudos realizados, seguido pelos documentos, utilizados em $27,03 \%$ das pesquisas, as entrevistas (semiestruturadas ou estruturadas), utilizadas em $21,62 \%$ dos artigos e as observaçóes, em 10,81\%. O grupo de foco foi empregado em um único estudo, o que corresponde a um nível de utilização de $2,70 \%$ em relação ao total.

Diante disso, constata-se que $37,84 \%$ dos artigos utiliza técnicas de coleta de dados mais usuais, como questionários, entrevistas e documentos, o que parece estar relacionado ao escopo e às demandas das pesquisas aplicadas ao campo das ciências sociais.

\subsection{Sugestáo de estudos futuros}

Buscando colaborar com o desenvolvimento da área de gestáo estratégica em empresas familiares, bem como auxiliar os pesquisadores a identificarem temas para estudos futuros, esta seção apresenta uma consolidação das principais lacunas de pesquisa apontadas nos artigos analisados.

Desta forma, a Figura 4 demonstra os principais temas referidos nos artigos como lacunas para estudos futuros, correlacionando-os com os blocos temáticos identificados anteriormente na Figura 3.

Figura 4 - Sugestōes para pesquisas futuras

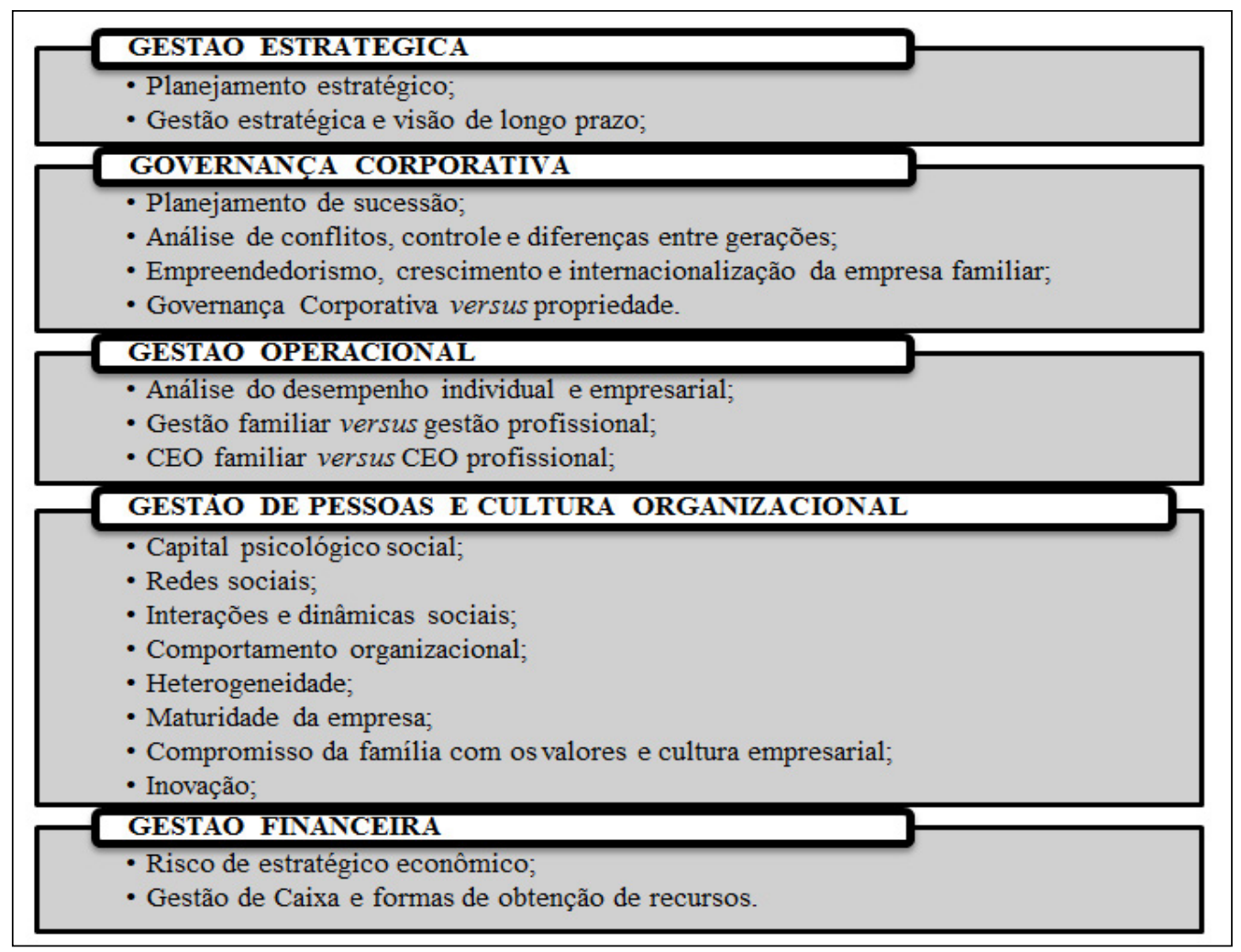

Fonte: elaborado pelos autores. 
Vale ressaltar que para esta análise considerou-se como sugestão de estudos futuros apenas as lacunas que realmente poderão contribuir com o avanço do conhecimento na área de pesquisa (gestấo estratégica em empresas familiares). Sendo assim, sugestốes como "ampliar a amostra de empresas investigadas", "ampliar estudos empíricos", "replicar o estudo em outros países, culturas, empresas maiores/menores" etc., apesar de mencionadas na maioria dos artigos estudados, foram desconsideradas para fins desta análise, visto que podem não trazer contribuiçōes específicas para o avanço teórico e empírico da área.

Discutidos os resultados obtidos com a realização deste metaestudo, na próxima seção são apresentadas as consideraçôes finais dos autores.

\section{CONSIDERAÇÓES FINAIS}

Este artigo buscou identificar as abordagens teóricas e metodológicas predominantes nos 39 estudos sobre gestão estratégica em empresas familiares, publicados entre o período de 2010 a 2015.

A análise dos estudos selecionados permitiu identificar que a maioria (82,05\%) foram publicados em revistas que possuem fator de impacto, o que demonstra a qualidade dos estudos efetuados. Apesar disso, 17,95\% dos estudos foram publicados em revistas sem fator de impacto, o que também demonstra o potencial de incremento e qualificação dos estudos envolvendo esta temática.

Outro aspecto a ser destacado se refere a concentração de publicaçôes que utilizam um mesmo artigo como referência. Das 327 citaçóes recebidas pelos 15 artigos mais citados, "Variations in R\&D Investments of Family and Nonfamily Firms: Behavioral Agency and Myopic Loss Aversion Perspectives" aparece 74 vezes (23\%). Esta quantidade de citaçóes, aliada ao fato deste artigo ter sido publicado somente em 2012, demonstra a relevância deste estudo dentro da temática envolvendo gestão estratégica em empresas familiares.

A possibilidade de estudos a serem realizados envolvendo a temática também se mostra variada, visto que a partir da análise dos artigos emergiram 5 blocos temáticos, a saber: gestão estratégica, governança corporativa, gestão operacional, gestão de pessoas e cultura organizacional e gestão financeira. A segmentação em blocos temáticos permite o aprofundamento dos estudos em áreas mais específicas, o que pode contribuir para a caracterização e reconhecimento do tema como um campo acadêmico independente - ainda em estágio inicial, conforme Stewart e Miner (2011).

Além disso, destaca-se o fato de que um terço dos artigos analisados não utilizaram abordagens teóricas em suas pesquisas, enquanto que outros estudos foram conduzidos à luz de teorias variadas, sendo a RBV e Teoria da Agência as mais frequentes. Reforça-se a importância da utilização de abordagens teóricas para a condução de estudos, ao mesmo tempo que os resultados obtidos sugerem que o campo de pesquisa sobre estratégia em empresas familiares, por ainda não estar muito consolidado, não possui teorias próprias que possam embasar as investigaçóes acerca desta temática.

Outro aspecto analisado está relacionado a identificaçáo das lacunas e sugestôes de estudos futuros apresentados pelos autores dos artigos, sendo as sugestóes consolidadas com base nos blocos temáticos identificados nos artigos analisados. Espera-se que estas 
sugestóes possam auxiliar os pesquisadores de gestão estratégica em empresas familiares a direcionarem os seus estudos.

Acredita-se que os objetivos estabelecidos para esta pesquisa foram alcançados, no entanto, o estudo apresenta algumas limitaçóes que devem ser destacadas. A primeira referese ao fato do estudo ter sido realizado apenas em publicaçóes de língua inglesa ou espanhola. Seria interessante a realização desta análise em revistas e eventos brasileiros, buscando identificar o que vem sem pesquisado sobre gestão estratégica em empresas familiares a nível nacional.

Outra limitação diz respeito à análise de artigos publicados em periódicos, desprezando as publicaçóes em eventos científicos. Assim, sugere-se que pesquisas futuras realizem a análise de artigos disponíveis em outros outlets, além dos periódicos.

É importante ressaltar, ainda, que este estudo é resultado da seleção de artigos através de palavras-chave específicas em busca realizada em outubro de 2015. Como a ciência está em constante evolução, novos estudos podem ter sido publicados após esta data e não estão contemplados nesta análise. Dessa forma, pesquisas futuras, ainda que utilizando os mesmos procedimentos deste estudo, possivelmente encontrarão um quadro teórico distinto do aqui apresentado. Além disso, atualizar ou confirmar os achados por meio de pesquisa empírica junto a associaçóes e pesquisadores que se ocupam da disciplina de empresas familiares apresenta-se, também, como uma possibilidade de avanço desta pesquisa.

Por fim, espera-se que este artigo seja uma contribuição para os pesquisadores interessados na temática de gestão estratégica em empresas familiares, apresentando um panorama das pesquisas já realizadas, bem como apontando alguns direcionamentos para pesquisas futuras.

\section{REFERÊNCIAS}

ACQUAAH, M. Social networking relationships, firm-specific managerial experience and firm performance in a transition economy: a comparative analysis of family owned and nonfamily firms. Strategic Entrepreneurship Journal, v. 1228, p. 1215-1228, 2012.

AGUILAR, J. L. E.; LEMA, D. G. P. de. La cultura de las empresas familiares turísticas mexicanas y su influencia en la gestión. Cuadernos de Administración, v. 24, n. 42, p. 295-313, 2011.

ALTINDAG, E; ZEHIR, C.; ACAR, A.Z. Learning, Entrepreneurship And Innovation Orientations In Turkish Family-Owned Firms. Emerging Markets Journal, v. 1, p. 3647, 2011.

ANDERSON; R. C.; REEB, D. Founding-Family Owner and Firm Performance: Evidence from the S\&P500. Journal of Finance, v. 58, p. 1302-1328, 2003. 
ARREGLE, L.; HITT, M. A.; SIRMON, D. G.; VERY, P. The Development of Organizational Social Capital: Attributes of Family Firms. Journal of Management Studies, v. 44, p. 73-95, 2007.

BARNEY, J.B; HESTERLY, W.S. Administraçáo Estratégica e Vantagem Competitiva: casos brasileiros. São Paulo: Pearson, 2007.

BENNEDSEN, M.; PÉREZ-GONZALEZ, F; WOLFENZON, D. Do CEOs Matter? Working Paper. Columbia and Stanford University, 2010.

BIRD, B.; WELSCH, H.; ASTRACHAN, J. H.; PISTRUI, D. Family business research: The evolution of an academic field. Family Business Review, v. 15, n. 4, p. 337-350, 2002.

BOYD, B.; HOLLENSEN, S. Strategic management of a family-owned airline : Analysing the absorptive capacity of Cimber Sterling Group A/S. Journal of Family Business Strategy, v. 3, n. 2, p. 70-78, 2012.

CALDAS, M. P.; TONELLI, M. J.; LACOMBE, B. M. B. Espelho, Espelho Meu: Metaestudo da Produção Científica em Recursos Humanos nos ENANPADs da Década de 90. In: Encontro da Associação Nacional de Pós-Graduação e Pesquisa em Administração, 2002, Anais... ANPAD, 2002.

CARNEY, M. Corporate governance and competitive advantage. Entrepreneurship Theory and Practice, v. 29, n. 3, 249-26, 2005.

CARR, J. C.; COLE, M. S.; RING, J. K.; BLETTNER, D. P. A Measure of Variations in Internal Social Capital Among Family Firms. Entrepreunership: Theory and Practice, p. 1207-1228, 2011.

CHEN, Y.; LIU, H.; NI, Y.; WU, M. A rational normative model of international expansion: Strategic intent perspective, market positions, and founder CEOs / familysuccessor CEOs. Journal of Business Research, p. 1-5, 2015.

CHIRICO, F.; SIRMON, D. G.; SCIASCIA, S.; MAZZOLA, P. Resource Orchestration in Family Firms: Investigating How Entrepreneurial Orientation, Generational Involvement , and Participative Strategy Affect Performance. Strategic Entrepreneurship Journal, v. 5, p. 307-326, 2011.

CHIRICO, F.; SALVATO, C. Knowledge Integration and Dynamic Organizational Adaptation in Family Firms. Family Business Review, v. 21, n. 2, p. 169-181, 2008.

CHRISMAN, J. J.; CHUA, J.H.; PEARSON, A. W.; BARNETT, T. Family involvement, family influence, and family centered non economic goals in small firms. Entrepreneurship Theory and Practice, v. 36, n. 2, p. 267-293, 2012. 
CHRISMAN, J. J.; SHARMA, P.; STEIER, L.; CHUA, J. The Influence of Family Goals, Governance, and Resources on Firm Outcomes. Entrepreunership: Theory and Practice, p. 1249-1262, 2013.

CHRISMAN, J. J.; PATEL, P. C. Variations in R\&D investments of family and nonfamily firms: behavioral agency and myopic loss aversion perspectives. Academy of Management Journal, v. 55, n. 4, p. 976-997, 2012.

CHRISMAN, J. J.; CHUA, J.H.; STEIER, L. An introduction to theories of family business, Journal of Business Venturing, p. 441-448, 2003.

CHRISMAN, J. J.; CHUA, J.H.; SHARMA, P. Trends and directions in the development of a strategic management theory of the family firm. Entrepreneurship Theory and Practice, v. 29, n. 5, p. 555-575, 2005.

CHRISMAN, J. J.; CHUA, J.H.; SHARMA, P. Defining the Business by Behavior. Entrepreneurship: Theory and Pratice, 1999.

CHUA, J. H.; CHRISMAN, J. J.; SHARMA, P. Defining the family business by behavior. Entrepreneurship Theory and Practice, v. 23, n. 4, p. 19-39, 1999.

DE CLERCQ, D.; BELAUSTEGUIGOITIA, I. Intergenerational strategy involvement and family firms' innovation pursuits: The critical roles of conflict management and social capital. Journal of Family Business Strategy, 2015.

CUCCULELLI, M.; MANNARINO, L.; PUPO, V.; RICOTTA, F. Ownermanagement, firm age, and productivity in Italian Family Firms. Journal of Small Business Management, v. 52, n. 2, p. 325-343, 2014.

DASPIT, J. J.; LONG, R. G. Mitigating Moral Hazard in Entrepreneurial Networks: Examining Structural and Relational Social Capital in East Africa. Entrepreunership: Theory and Practice, p. 1343-1350, 2014.

DE MASSIS, A.; SHARMA, P.; CHUA, J. H.; CHRISMAN, J. J. Family Business Studies: An annotated bibliography. Edward Elgar Publishing Inc, 2012.

DETIENNE, D. R.; CHIRICO, F. Exit Strategies in Family Firms: How Socioemotional wealth drives the threshold of Performance. Entrepreunership: Theory and Practice, p. 1297-1319, 2013.

DRESCH, A.; LACERDA, D.P.; ANTUNES, J.A.V. Design Science Research: Método de pesquisa para avanço da ciência e tecnologia. São Paulo, Bookman, 2015.

EDDLESTON, K. A.; KELLERMANNS, F. W.; ZELLWEGER, T. M. Exploring the Entrepreneurial Behavior of Family Firms: Does the Stewardship Perspective Explain Differences? Entrepreunership: Theory and Practice, p. 347-368, 2012. 
EDDLESTON, K. A.; KELLERMANNS, F. W.; FLOYD, S. W.; CRITTENDEN, V. L.; CRITTENDEN, W. F. Planning for Growth: Life Stage Differences in Family Firms. Entrepreunership: Theory and Practice, p. 1177-1203, 2013.

EISENHARDT, K. Control Organizacional and Economic Approaches. Management Science, v. 31, p. 134-139, 1985.

. Agency Theory: An Assessment and Review. The Academy of Management Review, v. 14, n. 1, p. 57-74, 1989.

FERNÁNDEZ-ROCA, F. J. The strategies of the Spanish cotton textile companies before the Civil War: The road to longevity. Business History, v. 54, n. 7, p. 1023-1054, 2012.

FISS, P.C.; ZAJAC, E.J. The diffusion of ideas over contested terrain: the (non) adoption of a shareholder value orientation among German firms. Administrative Science Quarterly. v. 49, p. 501-534, 2004.

FLEMONS, D. G.; COLE, P. M. Connecting and separating family and business: A relational approach to consultation. Family Business Review. v. 5, n. 3, p. 257-269, 1992.

GEGA, E.; VUKAJ, H; ELMAZI, L. Normative, social and cognitive predictors of entrepreneurial interest of College students in Albania. International Journal of Management Cases, p. 290-297, 2011.

GERSICK, K. E.; HAMPTON, M. M.; LANSBERG, I.; DAVIS, J. A. Generation to generation: Life cycles of the family business. Boston: Harvard Business School Press, 1997.

GÓMEZ-MEJÍA, L. R.; HAYNES, K. T.; NUNEEZ-NIQUEL, M.; JACOBSON, K. J. L.; MOYANO-FUENTES, J. Socioemotional Wealth and Business Risk in FamilyControlled Firms: Evidence from Spanish Olive Oil Mills. Administrative Science Quarterly. v. 52, n. 1, p. 106-137, 2007.

GÓMEZ-MEJÍA, L. R.; NUÑEZ-NIQUEL, M.; GUTIERREZ, I. The Role of Family Ties in Agency Contracts. Academy of Management Journal. v. 44, p. 81-95, 2001.

HARRIS, D.; MARTINEZ, J.L.; WARD, J.L. Is strategy different for the family owned businesses? Family Business Review, v. 7, n. 2, 159-176, 1994.

HENDRIKSEN, E.S.; VAN BREDA M.F. Teoria da Contabilidade. São Paulo: Atlas, 1999.

HOCAYEN-DA-SILVA, A. J.; ROSSINI, L.; FERREIRA JÚNIOR, I. Administração pública e gestão social: a produção científica brasileira entre 2000 e 2005 . Revista de Administraçáo Pública, v. 42, n. 4, p. 655-680, 2008. 
HOLT, D. T. Strategic Decisions Within Family Firms: Understanding the Controlling Family's Receptivity to Internationalization. Entrepreunership: Theory and Practice, p. 1145-1152, 2012.

JARZABKOWSKI, P.; SPEE, P. A. Strategy-as-practice: A review and future directions for the field. International Journal of Management Reviews, v. 11, n. 1, 69-95. 2009.

JASKIEWICZ, P.; LUCHAK, A. A. Explaining Performance Differences Between Family Firms With Family and Nonfamily CEOs: It's the Nature of the Tie to the Family That Counts! Entrepreunership: Theory and Practice, p. 1361-1368, 2013.

JONES, O.; GHOBADIAN, A. O`REGAN, N.; ANTCLIFF, V. Dynamic capabilities in a sixth-generation family firm: Entrepreneurship and the Bibby Line. Business History, p. 37-41, 2013.

KLEIN, A. Z.; SILVA, L. V. da; MACHADO, L.; AZEVEDO, D. Metodologia da pesquisa em administraçáo: uma abordagem prática. São Paulo: Atlas, 2015.

KOTLAR, J.; DE MASSIS, A.; FANG, H.; FRATTINI, F. Strategic reference points in family firms. Small Business Economics, v. 43, p. 597-619, 2014.

KOTLAR, J.; DE MASSIS, A. Goal Setting in Family Firms: Goal Diversity, Social Interactions, and Collective Commitment to Family-Centered Goals. Entrepreunership: Theory and Practice, p. 1263-1289, 2013.

LANSBERG, I. Succeeding generations: Realizing the dream of families in business. Cambridge: Harvard Business School Press, 1999.

LIONZO, A.; ROSSIGNOLI, F. Knowledge integration in family SMEs : an extension of the 4I model. Journal of Management \& Governance, p. 583-608, 2013.

LOZANO, M. B. Strategic decisions of family firms on cash accumulation. RAE Revista de Administraçáo de Empresas, v. 55, n. 4, p. 461-467, 2015.

LUMPKIN, G. T.; BRIGHAM, K. H. Long-Term Orientation and Intertemporal Choice in Family Firms. Entrepreunership: Theory and Practice, p. 1149-1170, 2011.

LUMPKIN, G. T.; STEIER, L.; WRIGHT, M. Strategic entrepreneurship in family business. Strategic Entrepreneurship Journal, v. 5, p. 285-306, 2011.

MAHTO, R. V.; DAVIS, P. S.; PEARCE II, J. A.; ROBINSON JR., R. B. Satisfaction with firm performance in family businesses. Entrepreunership: Theory and Practice, p. 985-1003, 2010. 
MEMILI, E.; WELSH, D. H. B.; LUTHANS, F. Going beyond research on goal setting: a proposed role for organizational psychological capital of family firms.

Entrepreunership: Theory and Practice, p. 1289-1297, 2013.

MILLER, D.; LE BRETON-MILLER, I.; LESTER, R. H. Family ownership and acquisition bahavior in publicly-traded companies. Strategic Management Journal, v. 31, p. 201-223, 2010.

MILLER, D.; LE BRETON-MILLER, I. Managing for the long run: Lessons in competitive advantage from great family businesses. Boston: Harvard Business School Press, 2005.

MINTZBERG, H.; LAMPEL, J.; QUINN, J. B.; GHOSHAL, S. O processo da estratégia: conceitos, contextos e casos selecionados. 4. ed. Porto Alegre: Bookman, 2006.

NAG, R.; HAMBRICK, D. C.; CHEN, M. J. What is strategic management, really? Inductive derivation of a consensus definition of the field. Strategic Management Journal, v. 28, n. 9, p. 935-955, 2007.

O'REGAN, N. O.; HUGHES, T.; COLLINS, L.; TUCKER, J. Strategic Thinking in Family Businesses. Strategic Change, v. 19, p. 57-76, 2010.

PAIVA, K. C. M.; OLIVEIRA, M. C. S. M.; MELO, M. C. O. L. Produção científica brasileira sobre empresa familiar - um metaestudo de artigos publicados em anais de eventos da ANPAD no período de 1997-2007, RAM, Rev. Adm. Mackenzie (Online), v. 9, n. 6, p. 148-173, 2008.

PALMER, D. The economics and politics of structure. Administrative Science Quarterly. v. 32, n. 1, p. 25-48, 1987.

PATEL, P. C.; CHRISMAN, J. J. Risk abatement as a strategy for R\&D investiments in family firms. Strategic Entrepreneurship Journal, v. 627, p. 617-627, 2014.

PATEL, V. K.; PIEPER, T. M.; HAIR JR., J. F. The global family business: Challenges and drivers for cross-border growth. Business Horizons, v. 55, n. 3, p. 231-239, 2012.

PONTES, A. S. M. Análise do tema gestão estratégica nas pequenas empresas prestadoras de serviços: uma revisão bibliográfica. Navus - Revista de Gestáo e Tecnologia. v. 2, n. 2, p. 26-32, 2012

PORTER, M. Competiçáo. Rio de Janeiro: Elsevier, 2009.

POZA, E. J. Family business. Mason, OH: Thomson South-Western, 2007. 
RAMÍREZ, J. B. B.; GÓMEZ-BETANCOURT, G.; VERGARA, M. P. L. Aproximación a los factores que influyen en la visión del patrimonio en las empresas familiares colombianas. Estudios Gerenciales, v. 27, p. 165-183, 2011.

ROMERO, A. D. M.; SOLIS, E. R. R.; MONROY, V. I. B. Strategic orientations and their relationship with performance: a case os a Mexican family firm. Academy of Strategic Management Journal, v. 13, n. 2, p. 1-21, 2014.

SHANKER, M.C.,; ASTRACHAN, J.H. 1996. Myths and realities: family business's contribution to US economy - A framework for assessing family business statistics,

Family Business Review, v. 9, n. 2, p. 107-123, 1996.

SHARMA, P. An overview of family business studies: Current status and directions for the future. Family Business Review, v. 17, n. 1, p. 1-36, 2004.

SHARMA, P.; CHRISMAN, J. J.; GERSICK, K. 25 years of Family Business Review: An outlook on the past and perspectives for the future. Family Business Review, v. 25, n. 1, p. 5-15, 2012.

SHARMA, P.; CHRISMAN, J. J.; CHUA, J. H. Strategic management of the family business: Past research and future challenges. Family Business Review, 10, 1-36, 1997.

SHARMA, P.; CHUA, J. H. Asian family enterprises and family business research. Asia Pacific Journal of Management, v. 30, p. 641-656, 2013.

SHARMA, P.; SALVATO, C. Commentary: Exploiting and Exploring New Opportunities Over Life Cycle Stages of Family. Entrepreunership: Theory and Practice, p. 1199-1206, 2011.

SINGAL, M.; SINGAL, V. Concentrated ownership and family firm performance: does family control matter? Strategic Entrepreneurship Journal, v. 5, p. 373-396, 2011.

SOUZA, S. A. de; REINERT, J. N.; SPROSSER, R. L. Pesquisa brasileira em Administração: um meta-estudo em temáticas do período 2000-2009. In: II Encontro de Ensino e Pesquisa em Administração e Contabilidade, 2009, Anais... ANPAD, 2009.

STEWARD, A.; MINER, A.S. The Prospects for Family Business in Research universities. Journal of Family Business Strategy, v. 2, p. 3- 14, 2011.

TEECE, D.; PISANO, G.; SHUEN, A. Dynamic capabilities and strategic management. Strategic Management Journal, v. 18, n. 7, p. 509-533, 1997.

TERENCE, A. C. F. Planejamento estratégico como ferramenta de competitividade na pequena empresa. 2002. Dissertação de Mestrado. Universidade de São Paulo. 
Processo de criaçáo de estratégias em pequenas empresas. 2008. Tese de

Doutorado. Universidade de São Paulo.

WARD, J. L. If theories of family enterprise really do matter, so does change in management education. Entrepreneurship Theory and Practice, v. 30, n. 6, p. 887-895, 2006.

WENNBERG, K.; WIKLUND, J.; HELLERSTEDT, K.; NORDQVIST, M. Implications of intra-family and external ownership transfer of family firms: short-term and long-term performance differences. Strategic Entrepreneurship Journal, v. 5, p. 352-372, 2011.

WRIGHT, M.; CHRISMAN, J. J.; CHUA, J. H.; STEIER, L. P. Family enterprise and context. Entrepreunership: Theory and Practice, p. 1247-1261, 2014.

YU, J.; ZHOU, J. X.; WANG, Y. XI, Y. Reading Institutional Perspectives from Entrepreneur Stories. Journal of Small Business Management, v. 51, n. 2, p. 183-195, 2013.

\section{ANEXO 1 - Artigos selecionados para este metaestudo}

\begin{tabular}{|c|c|c|c|}
\hline No & Autores (ano) & Título do Artigo & Periódico \\
\hline 1 & LOZANO (2015) & $\begin{array}{l}\text { Strategic Decisions of Family Firms on Cash } \\
\text { Accumulation }\end{array}$ & $\begin{array}{c}\text { RAE: Revista de } \\
\text { Administração de Empresas }\end{array}$ \\
\hline 2 & $\begin{array}{c}\text { CLERCQ; } \\
\text { BELAUSTEGUIGOITIA } \\
(2015) \\
\end{array}$ & $\begin{array}{l}\text { Intergenerational strategy involvement and family } \\
\text { firms' innovation pursuits: The critical roles of } \\
\text { conflict management and social capital }\end{array}$ & $\begin{array}{c}\text { Journal of Family Business } \\
\text { Strategy }\end{array}$ \\
\hline 3 & CHEN et al. (2015) & $\begin{array}{l}\text { A rational normative model of international } \\
\text { expansion: Strategic intent perspective, market } \\
\text { positions, and founder CEOs/family-successor } \\
\text { CEOs }\end{array}$ & Journal of Business Research \\
\hline 4 & $\begin{array}{l}\text { PATEL; CHRISMAN } \\
(2014) \\
\end{array}$ & $\begin{array}{l}\text { Risk Abatement as a Strategy for R\&D Investments } \\
\text { in Family Firms }\end{array}$ & $\begin{array}{c}\text { Strategic Management } \\
\text { Journal } \\
\end{array}$ \\
\hline 5 & KOTLAR et al. (2014) & Strategic Reference Points in Family Firms & Small Business Economics \\
\hline 6 & $\begin{array}{l}\text { ROMERO; SOLIS; } \\
\text { MONROY (2014) }\end{array}$ & $\begin{array}{l}\text { Strategic Orientations and Their Relationship } \\
\text { With Performance: A Case of a Mexican Family } \\
\text { Firm }\end{array}$ & $\begin{array}{l}\text { Academy of Strategic } \\
\text { Management Journal }\end{array}$ \\
\hline 7 & WRIGHT et al. (2014) & Family Enterprise and Context & $\begin{array}{c}\text { Entrepreneurship: Theory \& } \\
\text { Practice }\end{array}$ \\
\hline 8 & DASPIT; LONG (2014) & $\begin{array}{l}\text { Mitigating Moral Hazard in Entrepreneurial } \\
\text { Networks: Examining Structural and Relational } \\
\text { Social Capital in East Africa }\end{array}$ & $\begin{array}{c}\text { Entrepreneurship: Theory \& } \\
\text { Practice }\end{array}$ \\
\hline 9 & $\begin{array}{l}\text { CUCCULELLI et al. } \\
(2014) \\
\end{array}$ & $\begin{array}{l}\text { Owner-Management, Firm Age, and Productivity } \\
\text { in Italian Family Firms }\end{array}$ & $\begin{array}{c}\text { Journal of Small Business } \\
\text { Management }\end{array}$ \\
\hline 10 & $\begin{array}{l}\text { KOTLAR; MASSIS } \\
(2013)\end{array}$ & $\begin{array}{l}\text { Goal Setting in Family Firms: Goal Diversity, } \\
\text { Social Interactions, and Collective Commitment to } \\
\text { Family-Centered Goals }\end{array}$ & $\begin{array}{c}\text { Entrepreneurship: Theory \& } \\
\text { Practice }\end{array}$ \\
\hline 11 & $\begin{array}{l}\text { MEMILI; WELSH; } \\
\text { LUTHANS (2013) }\end{array}$ & $\begin{array}{l}\text { Going Beyond Research on Goal Setting: } A \\
\text { Proposed Role for Organizational Psychological } \\
\text { Capital of Family Firms }\end{array}$ & $\begin{array}{c}\text { Entrepreneurship: Theory \& } \\
\text { Practice }\end{array}$ \\
\hline
\end{tabular}




\begin{tabular}{|c|c|c|c|}
\hline No & Autores (ano) & Título do Artigo & Periódico \\
\hline 12 & $\begin{array}{c}\text { DeTIENNE; CHIRICO } \\
(2013)\end{array}$ & $\begin{array}{l}\text { Exit Strategies in Family Firms: How } \\
\text { Socioemotional Wealth Drives the Threshold of } \\
\text { Performance }\end{array}$ & $\begin{array}{c}\text { Entrepreneurship: Theory \& } \\
\text { Practice }\end{array}$ \\
\hline 13 & $\begin{array}{l}\text { CHRISMAN et al. } \\
(2013)\end{array}$ & $\begin{array}{l}\text { The Influence of Family Goals, Governance, and } \\
\text { Resources on Firm Outcomes }\end{array}$ & $\begin{array}{c}\text { Entrepreneurship: Theory \& } \\
\text { Practice }\end{array}$ \\
\hline 14 & $\begin{array}{l}\text { EDDLESTON et al. } \\
(2013)\end{array}$ & $\begin{array}{l}\text { Planning for Growth: Life Stage Differences in } \\
\text { Family Firms }\end{array}$ & $\begin{array}{c}\text { Entrepreneurship: Theory \& } \\
\text { Practice }\end{array}$ \\
\hline 15 & $\begin{array}{l}\text { JASKIEWICZ, P; } \\
\text { LUCHAK (2013) }\end{array}$ & $\begin{array}{l}\text { Explaining Performance Differences Between } \\
\text { Family Firms With Family and Nonfamily CEOs: } \\
\text { It's the Nature of the Tie to the Family That } \\
\text { Counts! }\end{array}$ & $\begin{array}{c}\text { Entrepreneurship: Theory \& } \\
\text { Practice }\end{array}$ \\
\hline 16 & $\begin{array}{c}\text { LIONZO; } \\
\text { ROSSIGNOLI (2013) }\end{array}$ & $\begin{array}{l}\text { Knowledge integration in family SMEs: an } \\
\text { extension of the } 4 I \text { model }\end{array}$ & $\begin{array}{c}\text { Journal of Management \& } \\
\text { Governance }\end{array}$ \\
\hline 17 & $\begin{array}{l}\text { SHARMA; CHUA } \\
(2013)\end{array}$ & $\begin{array}{l}\text { Asian family enterprises and family business } \\
\text { research }\end{array}$ & $\begin{array}{c}\text { Asia Pacific Journal of } \\
\text { Management }\end{array}$ \\
\hline 18 & YU et al. (2013) & $\begin{array}{l}\text { Rural Entrepreneurship in an Emerging } \\
\text { Economy: Reading Institutional Perspectives from } \\
\text { Entrepreneur Stories }\end{array}$ & $\begin{array}{c}\text { Journal of Small Business } \\
\text { Management }\end{array}$ \\
\hline 19 & $\begin{array}{l}\text { JONES; GHOBADIAN; } \\
\text { REGAN (2013) }\end{array}$ & $\begin{array}{l}\text { Dynamic capabilities in a sixth-generation family } \\
\text { firm: Entrepreneurship and the Bibby Line }\end{array}$ & Business History \\
\hline 20 & ACQUAAH (2012) & $\begin{array}{l}\text { Social Networking Relationships, Firm-Specific } \\
\text { Managerial Experience and Firm Performance in } \\
\text { a Transition Economy: A Comparative Analysis of } \\
\text { Family Owned and Nonfamily Firms }\end{array}$ & $\begin{array}{l}\text { Strategic Management } \\
\text { Journal }\end{array}$ \\
\hline 21 & $\begin{array}{l}\text { CHRISMAN; PATEL } \\
\text { (2012) }\end{array}$ & $\begin{array}{l}\text { Variations in RひD Investments of Family and } \\
\text { Nonfamily Firms: Behavioral Agency and Myopic } \\
\text { Loss Aversion Perspectives }\end{array}$ & $\begin{array}{c}\text { Academy of Management } \\
\text { Journal }\end{array}$ \\
\hline 22 & $\begin{array}{l}\text { FERNANDEZ-ROCA } \\
\text { (2012) }\end{array}$ & $\begin{array}{l}\text { The Strategies of the Spanish Cotton Textile } \\
\text { Companies Before the Civil War: The Road to } \\
\text { Longevity }\end{array}$ & Business History \\
\hline 23 & HOLT (2012) & \begin{tabular}{|l|} 
Strategic Decisions Within Family Firms: \\
Understanding the Controlling Family's Receptivity \\
to Internationalization
\end{tabular} & $\begin{array}{c}\text { Entrepreneurship: Theory \& } \\
\text { Practice }\end{array}$ \\
\hline 24 & $\begin{array}{l}\text { EDDLESTON; } \\
\text { KELLERMANNS; } \\
\text { ZELLWEGER (2012) }\end{array}$ & $\begin{array}{l}\text { Exploring the Entrepreneurial Behavior of Family } \\
\text { Firms: Does the Stewardship Perspective Explain } \\
\text { Differences? }\end{array}$ & $\begin{array}{c}\text { Entrepreneurship: Theory \& } \\
\text { Practice }\end{array}$ \\
\hline 25 & $\begin{array}{l}\text { BOYD; HOLLENSEN } \\
\text { (2012) }\end{array}$ & $\begin{array}{l}\text { Strategic management of a family-owned airline: } \\
\text { Analysing the absorptive capacity of Cimber } \\
\text { Sterling Group A/S }\end{array}$ & $\begin{array}{l}\text { Journal of Family Business } \\
\text { Strategy }\end{array}$ \\
\hline 26 & $\begin{array}{l}\text { AGUILAR; LEMA } \\
\text { (2011) }\end{array}$ & $\begin{array}{l}\text { La Cultura de Las Empresas Familiares Turísticas } \\
\text { Mexicanas y su Influencia em La Gestión } \\
\text { Estratégica }\end{array}$ & $\begin{array}{l}\text { Cuadernos de } \\
\text { Administración }\end{array}$ \\
\hline 27 & $\begin{array}{l}\text { SHARMA; SALVATO } \\
\text { (2011) }\end{array}$ & $\begin{array}{l}\text { Commentary: Exploiting and Exploring New } \\
\text { Opportunities Over Life Cycle Stages of Family } \\
\text { Firms. }\end{array}$ & $\begin{array}{c}\text { Entrepreneurship: Theory \& } \\
\text { Practice }\end{array}$ \\
\hline 28 & $\begin{array}{l}\text { ALTINDAG; ZEHIR; } \\
\text { ACAR (2011) }\end{array}$ & $\begin{array}{l}\text { Learning, Entrepreneurship and Innovation } \\
\text { Orientations in Turkish Family-Owned Firms }\end{array}$ & $\begin{array}{c}\text { EMAJ: Emerging Markets } \\
\text { Journal }\end{array}$ \\
\hline 29 & $\begin{array}{c}\text { LUMPKIN; BRIGHAM } \\
(2011)\end{array}$ & $\begin{array}{l}\text { Long-Term Orientation and Intertemporal Choice } \\
\text { in Family Firms }\end{array}$ & $\begin{array}{c}\text { Entrepreneurship: Theory \& } \\
\text { Practice }\end{array}$ \\
\hline 30 & CARR et al. (2011) & $\begin{array}{l}\text { A Measure of Variations in Internal Social Capital } \\
\text { Among Family Firms }\end{array}$ & $\begin{array}{c}\text { Entrepreneurship: Theory \& } \\
\text { Practice }\end{array}$ \\
\hline 31 & $\begin{array}{l}\text { RAMÍREZ; GÓMEZ- } \\
\text { BETANCORT; } \\
\text { VERGARA (2011) } \\
\end{array}$ & $\begin{array}{l}\text { Aproximación a los factores que influyen en la } \\
\text { visión del patrimonio en las empresas familiares } \\
\text { colombianas }\end{array}$ & Estudios Gerenciales \\
\hline
\end{tabular}




\begin{tabular}{|c|c|c|c|}
\hline No & Autores (ano) & Título do Artigo & Periódico \\
\hline 32 & $\begin{array}{l}\text { GEGA; VUKAJ; } \\
\text { ELMAZI (2011) }\end{array}$ & $\begin{array}{l}\text { Normative, social and cognitive predictors of } \\
\text { entrepreneurial interest of college students in } \\
\text { Albania }\end{array}$ & $\begin{array}{l}\text { International Journal of } \\
\text { Management Cases }\end{array}$ \\
\hline 33 & CHIRICO et al. (2011) & $\begin{array}{l}\text { Resource orchestration in family firms: } \\
\text { investigating how entrepreneurial orientation, } \\
\text { generational involvement, and participative } \\
\text { strategy affect performance }\end{array}$ & $\begin{array}{c}\text { Strategic Entrepreneurship } \\
\text { Journal }\end{array}$ \\
\hline 34 & $\begin{array}{l}\text { WENNBERG et al. } \\
\qquad(2011)\end{array}$ & $\begin{array}{l}\text { Implications of intra-family and external } \\
\text { ownership transfer of family firms: short-term and } \\
\text { long-term performance differences }\end{array}$ & $\begin{array}{c}\text { Strategic Entrepreneurship } \\
\text { Journal }\end{array}$ \\
\hline 35 & $\begin{array}{l}\text { LUMPKIN; STEIER; } \\
\text { WRIGHT (2011) }\end{array}$ & Strategic entrepreneurship in family business & $\begin{array}{l}\text { Strategic Entrepreneurship } \\
\text { Journal }\end{array}$ \\
\hline 36 & $\begin{array}{l}\text { SINGAL; SINGAL } \\
(2011)\end{array}$ & $\begin{array}{l}\text { Concentrated ownership and firm performance: } \\
\text { does family control matter? }\end{array}$ & $\begin{array}{c}\text { Strategic Entrepreneurship } \\
\text { Journal } \\
\end{array}$ \\
\hline 37 & $\begin{array}{l}\text { MILLER; LE BRETON- } \\
\text { MILLER; LESTER } \\
(2010)\end{array}$ & $\begin{array}{l}\text { Family Ownership and Acquisition Behavior in } \\
\text { Publicly-traded Companies }\end{array}$ & $\begin{array}{c}\text { Strategic Management } \\
\text { Journal }\end{array}$ \\
\hline 38 & O'REGAN et al. (2010) & Strategic thinking in family businesses. & Strategic Change \\
\hline 39 & MAHTO et al. (2010) & $\begin{array}{l}\text { Satisfaction With Firm Performance in Family } \\
\text { Businesses }\end{array}$ & $\begin{array}{c}\text { Entrepreneurship: Theory \& } \\
\text { Practice }\end{array}$ \\
\hline
\end{tabular}

Fonte: revisão sistemática de literatura. 